\title{
ПРАВОВОЕ РЕГУЛИРОВАНИЕ СОВМЕСТИТЕЛЬСТВА В ОРГАНАХ ВНУТРЕННИХ ДЕЛ (ПОЛИЦИИ)
}

\begin{abstract}
Аннотация: Расссмотриваются основные направления правового регулирования совместительства в органах внутренних дел.Отмечается, что в настоящее время режим совместительства сотрудников органов внутренних дел полиции необходимо определить на законодательном уровне. Целесообразно использовать зарубежный опыт и официально разрешить совместительство сотрудникам органов внутренних дел в коммерческих организациях, если таковое не будет создавать "конфлликт интересов на государственной службе». Предусмотреть ряд обязанностей, осуществляющих совместительство: совместительство сотрудников органов внутренних дел вне системы МвД России может осуществляться только с согласия руководства органа внутренних дел; сотрудники органов внутренних дел, осуществляя трудовые функции в коммерческих организациях, не могут использовать ресурсы органов внутренних дел в интересах своего совместительства. Методологическую основу статьи составили современные достижения теории познания. В процессе исследования применялись общефилософрский, теоретический, общефилософские методы, традиционно правовые методы, а также методы, используемые в конкретно-социологических исследованиях. Трудовое законодательство о работе по совместительству: Статьей 282 ТК РФ установлено, что совместительство - это выполнение сотрудником другой регулярной оплачиваемой работы на условиях трудового договора в свободное от основной работы время. Более подробно труд совместителей регламентирован гл. 44 ТК РФ. Основными признаками совместительства является то, что: работник имеет основное место работы (то есть уже состоит в трудовых правоотношениях с тем же или иным работодателем); работа выполняется в свободное от основной работы время; работа выполняется на условиях отдельного трудового договора.
\end{abstract}

Ключевые слова: принуждение, ограничение, запрет, полицейский, полиция, сотрудник, служба, совместитеьство, коррупция, увольнение.

$\mathrm{T}$ рудовое законодательство о работе по совместительству: Статьей 282 ТК РФ установлено, что совместительство - это выполнение сотрудником другой регулярной оплачиваемой работы на условиях трудового договора в свободное от основной работы время. Более подробно труд совместителей регламентирован гл. 44 ТК РФ. Основными признаками совместительства является то, что:

- работник имеет основное место работы (то есть уже состоит в трудовых правоотношениях с тем же или иным работодателем);

- работа выполняется в свободное от основной работы время;

- работа выполняется на условиях отдельного трудового договора.

Трудовое законодательство исходит из того, что работа по совместительству не может быть единственной для работника, то есть обязательно должно быть основное место работы. Вместе с тем законодательством РФ не предусмотрена ответственность работодателя за оформление работни- ка по совместительству при отсутствии у последнего основного места работы.

В ст. 60.1 ТК РФ определено два вида совместительства:

- внутреннее (работа в той же организации в свободное от работы время);

- внешнее (работа по трудовому договору, заключенному с другим работодателем).

Трудовой кодекс содержит запрет для некоторых категорий сотрудников на работу по совместительству, к коим до принятия закона службе в органах внутренних дел» относились и сотрудники полиции.

Раньше ТК РФ устанавливал продолжительность работы по совместительству не более 16 часов в неделю. В настоящее время длительность рабочего времени совместителя увеличилась до 20 часов в неделю (не более 4-х часов в день) (ст. 284 ТК РФ). Законодатель допускает, что в дни, когда по основному месту работы сотрудник свободен от исполнения трудовых обязанностей, он может работать по совместительству полный рабочий 
день или смену. Если по основному месту работы сотрудник приостановил работу в связи с задержкой выплаты заработной платы на срок более 15 дней (ч. 2 ст. 142 ТК РФ) или отстранен от работы на определенный срок (ч. 2, 4 ст. 73 ТК РФ), необходимо контролировать количество часов, которое он отрабатывает. В любом случае продолжительность работы по совместительству ограничена половиной месячной нормы рабочего времени за месяц или другой учетный период.

Работа совместителя оплачивается по существующим расценкам (тарифам, ставкам, окладам) в зависимости от отработанного времени либо выработки. При этом учитываются все причитающиеся коэффициенты и надбавки. При установлении совместителям с повременной оплатой труда нормированных заданий оплата производится по конечным результатам за фактически выполненный объем работ (ст. 285 ТК РФ). Если условия труда, работы по совместительству являются особыми, отклоняющимися от нормальных, то оплата труда производится в повышенном размере (ст. 146 ТК РФ).

Отдельные нормативные акты устанавливают правила о выплате совместителям, работающим в бюджетных учреждениях, процентных надбавок за непрерывный стаж работы. Все условия оплаты работ, выполняемых в порядке совместительства, должны быть указаны в трудовом договоре.

Практически все гарантии и компенсации, предусмотренные Трудовым кодексом, локальными нормативными актами, коллективными договорами, соглашениями, распространяются на совместителя.

Совместителю полагается ежегодный оплачиваемый отпуск, который предоставляется одновременно с отпуском по основной работе (ст. 286 ТК РФ).

Если в порядке совместительства работник занимает должность (выполняет работу), по которой законом предусмотрен удлиненный ежегодный оплачиваемый отпуск, то ему должен предоставляться такой же удлиненный отпуск.

Если на работе по совместительству продолжительность ежегодного оплачиваемого отпуска меньше, чем по основному месту работы, организация обязана предоставить по письменному заявлению работника отпуск без сохранения заработной платы. Продолжительность такого отпуска равна разнице между отпуском по основному месту работы и отпуском по месту работы по совместительству.
Трудовой договор с совместителем расторгается по тем же основаниям, что и с основными работниками (ст. ст. 77, 81 ТК РФ). Но ст. 288 ТК РФ устанавливает дополнительное основание расторжения трудового договора: прием работника, для которого эта работа будет являться основной. Специалист кадровой службы учреждения в этом случае должен предупредить сотрудника в письменной форме не позднее чем за 2 недели до расторжения трудового договора или служебного контракта.

Отличие совместительства от совмещения:

Нередко путаются два понятия «совместительство» и «совмещение». Понятие совмещения дано в ст. 60.2 ТК РФ - выполнение дополнительной работы по другой или такой же профессии (должности), наряду с работой, определенной трудовым договором. Такая работа выполняется в течение установленной продолжительности рабочего дня (смены) и только с письменного согласия работника. Оплата ее осуществляется дополнительно.

В соответствии с ч. 3 ст. 60.2 ТК РФ срок, в течение которого работник будет выполнять дополнительную работу, устанавливается с его письменного согласия работодателем.

Основное различие между совместительством и совмещением - то, что при совместительстве выполняемая работа осуществляется помимо основной, а при совмещении - наряду с основной работой в течение продолжительности рабочего дня (смены).

Федеральный закон от 30.11.2011 N 342-Ф3 «0 службе в органах внутренних дел Российской Федерации и внесении изменений в отдельные законодательные акты Российской Федерации» в статья 34. «Совмещение обязанностей на службе в органах внутренних дел. Совместительство» устанавливает правила совместительства в органах внутренних дел. Законодатель впервые узаконил совместительство в органах внутренних дел:

1. С согласия руководителя федерального органа исполнительной власти в сфере внутренних дел или уполномоченного руководителя сотрудник органов внутренних дел наряду с выполнением обязанностей по замещаемой должности в органах внутренних дел имеет право выполнять обязанности по иной должности в органах внутренних дел (совмещать обязанности).

2. Совмещение обязанностей на службе в органах внутренних дел допускается при условии, что это не влечет за собой ухудшение выполнения сотрудником органов внутренних дел обязанностей 
Полицейское право

\begin{tabular}{|c|c|c|}
\hline Характеристика & Совместительство & Совмещение \\
\hline $\begin{array}{l}\text { Наличие трудового } \\
\text { договора }\end{array}$ & Обязательно заключение трудового договора & $\begin{array}{l}\text { Достаточно оформить дополнения в имеющийся } \\
\text { трудовой договор }\end{array}$ \\
\hline $\begin{array}{l}\text { Запись в трудовой } \\
\text { книжке }\end{array}$ & $\begin{array}{l}\text { По желанию работника по основному месту работы } \\
\text { (ст. 66 ТК РФ) }\end{array}$ & Не производится \\
\hline Испытательный срок & Устанавливается по соглашению сторон & Не устанавливается \\
\hline Оплата работы & $\begin{array}{l}\text { Регулируется ст. } 285 \text { ТК РФ. Осуществляется в зави- } \\
\text { симости от отработанного времени или выработки }\end{array}$ & $\begin{array}{l}\text { Производится в виде доплаты к оплате по ос- } \\
\text { новной работе. Размер доплаты устанавливается } \\
\text { соглашением сторон (ст. } 151 \text { ТК РФ). Районный } \\
\text { коэффициент и надбавки к заработной плате для } \\
\text { совмещения законодательством не устанавлива- } \\
\text { ются }\end{array}$ \\
\hline Нормирование труда & Устанавливается по общим правилам гл. 22 ТК РФ & Не устанавливается \\
\hline Отпуск & $\begin{array}{l}\text { Согласно ст. } 286 \text { ТК РФ предоставляется одновре- } \\
\text { менно с отпуском по основной работе }\end{array}$ & $\begin{array}{l}\text { Не предоставляется. Оплата отпуска производится } \\
\text { с учетом доплат за совмещение профессий }\end{array}$ \\
\hline $\begin{array}{l}\text { Гарантии } \\
\text { и компенсации }\end{array}$ & $\begin{array}{l}\text { Все гарантии, кроме гарантий и компенсаций ли- } \\
\text { цам, совмещающим работу и обучение }\end{array}$ & $\begin{array}{l}\text { Устанавливаются дополнительно в локальных } \\
\text { нормативных актах организации и в трудовом } \\
\text { договоре }\end{array}$ \\
\hline По ограничениям & $\begin{array}{l}\text { Статьей } 282 \text { ТК РФ введены такие ограничения: } \\
\text { возраст, вредные условия труда, государствен- } \\
\text { ные служащие, отдельные категории работников } \\
\text { (педагогические, медицинские и фармацевтические } \\
\text { работники, работники культуры), а также ст. } 276 \text { ТК } \\
\text { РФ установлены ограничения на работу по совме- } \\
\text { стительству руководителя организации - только с } \\
\text { разрешения уполномоченного органа юридического } \\
\text { лица либо собственника имущества организации }\end{array}$ & $\begin{array}{l}\text { Совмещение лицом, осуществляющим функции } \\
\text { единоличного исполнительного органа обще- } \\
\text { ства (директором, генеральным директором), } \\
\text { и членами коллегиального исполнительного } \\
\text { органа общества (правления, дирекции) долж- } \\
\text { ностей в органах управления других организаций } \\
\text { допускается только с согласия совета директоров } \\
\text { (наблюдательного совета) общества (п. } 3 \text { ст. } 69 \\
\text { Закона N 208-Ф3 <15>) }\end{array}$ \\
\hline Место работы & $\begin{array}{l}\text { Может осуществляться как по месту основной рабо- } \\
\text { ты, так и в других организациях }\end{array}$ & $\begin{array}{l}\text { Осуществляется в той организации, которая явля- } \\
\text { ется основным местом работы }\end{array}$ \\
\hline
\end{tabular}

по замещаемой должности в органах внутренних дел и не приводит к возникновению конфликта интересов.

Конфликт интересов в органах внутренних дел в соответствии со статьей 71 закона о службе в ОВД - ситуация, при которой личная заинтересованность (прямая или косвенная) сотрудника органов внутренних дел влияет или может повлиять на объективное выполнение им служебных обязанностей и при которой возникает или может возникнуть противоречие между личной заинтересованностью сотрудника и законными интересами граждан, организаций, общества или государства, способное привести к причинению вреда правам и законным интересам граждан, организаций, общества или государства.

3. Порядок и условия совмещения обязанностей на службе в органах внутренних дел устанавливаются Правительством Российской Федерации.

4. Работа сотрудников органов внутренних дел по совместительству не допускается, за исключением педагогической, научной и иной творческой деятельности, которая не приводит к возникновению конфликта интересов и не влечет за собой ухудшение выполнения сотрудником обя- занностей по замещаемой должности в органах внутренних дел. При этом педагогическая, научная и иная творческая деятельность не может финансироваться исключительно за счет средств иностранных государств, международных и иностранных организаций, иностранных граждан и лиц без гражданства, если иное не предусмотрено международным договором Российской Федерации или законодательством Российской Федерации. Об осуществлении такой деятельности сотрудник обязан уведомить непосредственного руководителя (начальника).(в ред. Федерального закона от 02.07.2013 N 185-ФЗ).

В последней редакции закона преподавательская деятельность заменена на педагогическую, что позволяет несколько расширить диапазон видов деятельности возможных при совместительстве.

Возвращаясь к пункту 3 статьи 34 закона «0 службе в ОВД» можно констатировать что порядок и условия совмещения обязанностей на службе в органах внутренних дел устанавливаются Постановлением Правительства РФ от 25 июня 2012 г. N 621 «Об утверждении Положения о совмещении обязанностей на службе в органах внутренних дел Российской Федерации». 
Положение устанавливает порядок и условия выполнения сотрудниками органов внутренних дел Российской Федерации наряду с выполнением служебных обязанностей по замещаемой должности в органах внутренних дел Российской Федерации обязанностей по иной должности в органах внутренних дел.

Совмещение обязанностей допускается в пределах подразделения центрального аппарата Министерства внутренних дел Российской Федерации, территориального органа Министерства внутренних дел Российской Федерации, образовательного учреждения, научно-исследовательской, медикосанитарной и санаторно-курортной организации системы Министерства внутренних дел Российской Федерации, окружного управления материальнотехнического снабжения системы Министерства внутренних дел Российской Федерации, а также иной организации и подразделения, созданных для выполнения задач и осуществления полномочий, возложенных на органы внутренних дел.

Совмещение обязанностей допускается по равнозначной или нижестоящей должности в органах внутренних дел (далее - должность), по которой установлены обязанности, аналогичные обязанностям по замещаемой сотрудником должности, либо по иной должности при условии, что сотрудник соответствует квалификационным требованиям по совмещаемой должности.

Совмещение обязанностей допускается по вакантным и невакантным должностям.

Совмещение обязанностей по невакантной должности допускается в случаях временной нетрудоспособности, пребывания в отпуске или в командировке, обучения с отрывом от выполнения служебных обязанностей, временного отстранения от выполнения служебных обязанностей сотрудника, замещающего эту должность.

Не допускается совмещение обязанностей:

a) сотрудниками, замещающими должности высшего начальствующего состава;

б) руководителями (начальниками) и их заместителями всех уровней;

в) по должностям, выполнение служебных обязанностей по которым предусматривает содержание, охрану и конвоирование задержанных, подвергнутых административному аресту и (или) заключенных под стражу лиц, находящихся в изоляторах временного содержания подозреваемых и обвиняемых органов внутренних дел;

г) по должностям, предусматривающим проведение уголовно-процессуальных действий, со- трудниками, не обладающими полномочиями по проведению уголовно-процессуальных действий по основной должности;

д) по должностям, предусматривающим проведение оперативно-розыскных мероприятий, сотрудниками, не обладающими полномочиями по проведению оперативно-розыскных мероприятий по основной должности.

Совмещение обязанностей может осуществляться по инициативе сотрудника или руководителя (начальника), имеющего право назначения на должность, с согласия сотрудника, выраженного в письменной форме. Совмещение обязанностей оформляется приказом руководителя (начальника), имеющего право назначения на должность. В приказе о совмещении обязанностей указываются объем и содержание обязанностей, возлагаемых на сотрудника по совмещаемой должности, срок (период), на который устанавливается совмещение обязанностей, а также размер дополнительной выплаты за совмещение обязанностей.

Общий размер дополнительной выплаты за совмещение обязанностей в течение полного календарного месяца не может превышать месячный оклад в соответствии с совмещаемой должностью, в том числе при совмещении обязанностей двумя и более сотрудниками.

Сотрудник вправе отказаться от совмещения обязанностей, предупредив об этом руководителя (начальника), имеющего право назначения на должность, в письменной форме не позднее чем за 3 рабочих дня до даты предполагаемого прекращения совмещения обязанностей.

Руководитель (начальник), имеющий право назначения на должность, вправе отменить приказ о совмещении обязанностей, предупредив об этом сотрудника в письменной форме не позднее чем за 3 рабочих дня до принятия соответствующего решения.

Руководитель (начальник), имеющий право назначения на должность, обязан в установленном порядке освободить сотрудника от совмещения обязанностей в случае:

а) если совмещение обязанностей повлекло за собой ухудшение выполнения сотрудником обязанностей по замещаемой должности или привело к возникновению конфликта интересов;

б) замещения вакантной должности, по которой сотрудник совмещает обязанности, другим сотрудником;

в) прекращения обстоятельств, предусмотренных пунктом 5 Положения; 
г) отказа сотрудника от совмещения обязанностей в порядке, установленном пунктом 11 Положения.

Решение о прекращении совмещения обязанностей оформляется приказом руководителя (начальника), имеющего право назначения на должность.

Делая выводы, отметим, что совместительство допускается в пределах подразделения центрального аппарата, территориального органа МВД России, организации или подразделения системы
Министерства. Совмещение возможно по равнозначной или нижестоящей должности. Условие - обязанности по совмещаемой должности аналогичны тем, что сотрудник выполняет по основной, либо он соответствует квалификационным требованиям по совмещаемой должности. Совмещение допускается по вакантным должностям, а в ряде случаев - и по невакантным (при временном отсутствии занимающего эту должность сотрудника изза болезни, отпуска, командировки, направления на учебу, отстранения).

\section{Библиография:}

1. Куракин А.В. Административно-правовое регулирование совмести-тельства в органах внутренних дел и проблемы противодействия коррупции // Российская юстиция. - 2007. - № 11

2. Костенников М.В., Куракин А.В. Административно-правовое противодействие коррупции в системе государственной службы и в деятельности сотрудников полиции Российской Федерации и зарубежных государств. // Полицейская деятельность. - 2011. - 1. - С. 10 - 16.

3. М.В. Костенников К вопросу о противодействии коррупции в полиции // Административное и муниципальное право. - 2013. - 1. - С. 49 - 50. DOI: 10.7256/1999-2807.2013.01.9.

4. М.В. Костенников, А.В. Куракин, И.Н. Кошелев Административно-правовое регулирование обеспечения собственной безопасности и противодействия коррупции в органах внутренних дел (ч. 2). // Административное и муниципальное право. - 2011. - 2. - С. 38 - 45.

5. Куракин А.В., Костенников М.В. Административно-правовое противодействие коррупции в системе государственной службы и в деятельности сотрудников полиции Российской Федерации и зарубежных государств // NB: Российское полицейское право. - 2013. - 1. - C. 65 - 83. DOI: 10.7256/2306-4218.2013.1.735. URL: http://www.enotabene.ru/pm/article_735.html

6. Костенников М.В., Куракин А.В., Кошелев И.Н. Административно-правовое регулирование обеспечения собственной безопасности и противодействия коррупции в органах внутренних дел (ч. 3 окончание начало в № 1 , 2 - 2011 г.) // Административное и муниципальное право. - 2011. - 4. - С. 52 - 61.

7. Куракин А.В., Горин Е.В. Антикоррупционный стандарт служебного поведения сотрудника Госавтоинспекции // Полицейская деятельность. - 2014. - 3. - С. 293 - 300. DOI: 10.7256/2222-1964.2014.3.12356.

8. Соломатина Е.А. Правовое регулирование деятельности полиции в зарубежных странах // NB: Российское полицейское право. - 2013. - 3. - С. 104 - 118. DOI: 10.7256/2306-4218.2013.3.8916. URL: http://www.e-notabene.ru/ pm/article_8916.html

9. Новоселов С.А., Трунцевский Ю.В. Повышение эффективности предупреждения преступлений и иных правонарушений, коррупционной направленности, совершаемых сотрудниками ГИБДД, как условие организации дальнейшего реформирования ОВД РФ согласно Дорожной карте // Административное и муниципальное право. 2013. - 4. - C. 321 - 326. DOI: 10.7256/1999-2807.2013.04.3.

10. Митрохин В.В. Административные процедуры прохождения службы в органах внутренних дел // Административное и муниципальное право. - 2014. - 2. - С. 128 - 140. DOI: 10.7256/1999-2807.2014.2.10841.

\section{References (transliterated):}

1. Kurakin A.V. Administrativno-pravovoe regulirovanie sovmesti-tel'stva $\mathrm{v}$ organakh vnutrennikh del i problemy protivodeistviya korruptsii // Rossiiskaya yustitsiya. - 2007. - № 11

2. Kostennikov M.V., Kurakin A.V. Administrativno-pravovoe protivodeistvie korruptsii v sisteme gosudarstvennoi sluzhby i v deyatel'nosti sotrudnikov politsii Rossiiskoi Federatsii i zarubezhnykh gosudarstv. // Politseiskaya deyatel'nost'. 2011. - 1. - C. $10-16$.

3. M.V. Kostennikov K voprosu o protivodeistvii korruptsii v politsii // Administrativnoe i munitsipal'noe pravo. - 2013. 1. - C. 49 - 50. DOI: 10.7256/1999-2807.2013.01.9.

4. M.V. Kostennikov, A.V. Kurakin, I.N. Koshelev Administrativno-pravovoe regulirovanie obespecheniya sobstvennoi bezopasnosti i protivodeistviya korruptsii v organakh vnutrennikh del (ch. 2). // Administrativnoe i munitsipal'noe pravo. - 2011. - 2. - C. $38-45$.

5. Kurakin A.V., Kostennikov M.V. Administrativno-pravovoe protivodeistvie korruptsii v sisteme gosudarstvennoi sluzhby i v deyatel'nosti sotrudnikov politsii Rossiiskoi Federatsii i zarubezhnykh gosudarstv // NB: Rossiiskoe politseiskoe pravo. 2013. - 1. - C. 65 - 83. DOI: 10.7256/2306-4218.2013.1.735. URL: http://www.e-notabene.ru/pm/article_735.html 


\section{Административное и муниципальное право $10(82) \cdot 2014$}

6. Kostennikov M.V., Kurakin A.V., Koshelev I.N. Administrativno-pravovoe regulirovanie obespecheniya sobstvennoi bezopasnosti i protivodeistviya korruptsii v organakh vnutrennikh del (ch. 3 okonchanie nachalo v № 1 , 2 - 2011 g.) // Administrativnoe i munitsipal'noe pravo. - 2011. - 4. - C. 52 - 61.

7. Kurakin A.V., Gorin E.V. Antikorruptsionnyi standart sluzhebnogo povedeniya sotrudnika Gosavtoinspektsii // Politseiskaya deyatel'nost'. - 2014. - 3. - C. 293 - 300. DOI: 10.7256/2222-1964.2014.3.12356.

8. Solomatina E.A. Pravovoe regulirovanie deyatel'nosti politsii v zarubezhnykh stranakh // NB: Rossiiskoe politseiskoe pravo. - 2013. - 3. - C. 104 - 118. DOI: 10.7256/2306-4218.2013.3.8916. URL: http://www.e-notabene.ru/pm/ article_8916.html

9. Novoselov S.A., Truntsevskii Yu.V. Povyshenie effektivnosti preduprezhdeniya prestuplenii i inykh pravonarushenii, korruptsionnoi napravlennosti, sovershaemykh sotrudnikami GIBDD, kak uslovie organizatsii dal'neishego reformirovaniya OVD RF soglasno Dorozhnoi karte // Administrativnoe i munitsipal'noe pravo. - 2013. - 4. - C. 321 - 326. DOI: 10.7256/1999-2807.2013.04.3.

10. Mitrokhin V.V. Administrativnye protsedury prokhozhdeniya sluzhby v organakh vnutrennikh del // Administrativnoe i munitsipal'noe pravo. - 2014. - 2. - C. 128 - 140. DOI: 10.7256/1999-2807.2014.2.10841. 